\title{
Partisipasi Generasi Muda Dalam Pengembangan Ekowisata Subak Sembung di Desa Peguyangan, Denpasar Bali
}

Ni Nyoman Astriani Giri a, 1, I Made Adikampana a, 2

1astrianigiri95@gmail.com,2adikampana@unud.ac.id

a Program Studi S1 Destinasi Pariwisata, Fakultas Pariwisata,Universitas Udayana, Jl. Dr. R. Goris, Denpasar, Bali 80232 Indonesia

\section{Abstract}

Subak Sembung Ecotourism has width of 155 hectares, administratively a part of Peguyangan village, North Denpasar subdistrict. The existence of this Subak Ecotourism is a green line left in Denpasar city. The purposes of this research are to determine the development of Subak Sembung as ecotourism destination in Peguyangan village, Denpasar, Bali and to determine about the role of youth generation of Subak Sembung Ecotourism development in Peguyangan village, Denpasar, Bali.

The data used in this research is qualitative data with the data sources in the form of primary data and secondary data. Those data collected using method of observation, in-depth interview, and literature study. The determining of informants done by purposive technique.

The result of this research show that the youth generation of Banjar Pulugambang actively participate in tourism activities such as involved in events that held by Subak Sembung Ecotourism manager. Their roles are as the guest greeters, classified in a cimittee as food and drinks keepers, handicraft accessories keepers, and also involved as a local guide, help in decorating, keep the environment clean, and do events such as fishing, guiding in making canang, outbound, teaching the tourists to painting and also teaching the tourist to dance. The theory of Tosun explains that the participation of youth generation from Banjar Pulugambang has done spontanly.

Keywords : Role of youth generation, Ecotourism development, Subak.

\section{PENDAHULUAN}

Sebagai suatu aktivitas manusia, pariwisata pada dasarnya merupakan fenomena perjalanan manusia secara perseorangan atau kelompok dengan berbagai macam tujuan asalkan bukan untuk mencari nafkah atau menetap. Manusia melakukan perjalanan secara bebas atau kemauan sendiri dengan tujuan damai untuk memenuhi kebutuhan hakikinya, yaitu untuk mengetahui, mempelajari, menemukenali, dan mengalami secara langsung segala sesuatunya yang tidak ada di tempat tinggalnya dan mencari suatu keunikan kekhasan baik alam, budaya maupun kondisi geografis yang berbeda-beda. Karena itu, daya tarik wisata yang beraneka ragam dan berbedabeda tersebut harus diakui dan dihargai serta dilestarikan. (Muljadi \& Warman, 2014)

Menurut Instruksi Presiden Republik Indonesia Nomor 19 Tahun 1969, kepariwisataan merupakan kegiatan jasa yang memanfaatkan kekayaan alam

dan lingkungan hidup yang khas, seperti hasil budaya, peninggalan sejarah, pemandangan alam yang indah dan iklim yang nyaman. Pada saat kegiatan kepariwisataan berlangsung, wisatawan melakukan berbagai aktivitas wisata guna memenuhi kebutuhan untuk keingintahuan. Aktivitas wisata yang dilakukan sangat beragam sesuai dengan motivasi dan minat wisatawan yang berkunjung kesuatu daerah tujuan pariwisata baik untuk berlibur, kunjungan sosial budaya, kunjungan usaha, kunjungan konvensasi dan pameran serta motivasi kunjungan lainnya. (Muljadi \& Warman, 2014)

Bali merupakan provinsi di Indonesia yang kaya dengan keindahan alam dan terkenal dengan destinasi pariwisatanya sehingga bali banyak dikunjungi oleh wisatawan baik wisatawan dari mancanegara maupun nusantara. Selain memiliki keindahan alam, terkenalnya Bali di dunia karena memiliki kebudayaan yang unik, peninggalan sejarah, serta peninggalan warisan budaya, seperti salah satu yang dimiliki Bali yaitu Subak. Subak adalah suatu organisasi petani sawah secara tradisional di Bali, dengan satu kesatuan areal sawah, serta umumnya satu sumber air selaku kelengkapan pokoknya. (Kaler, 1985) Di kawasan Desa Peguyangan, Denpasar, Bali, memiliki warisan budaya Subak yang diberi nama Subak Sembung yang memiliki areal persawahan seluas 115 hektar dengan hamparan persawahan hijau yang masih alami 
yang dikelola oleh para petani dari beberapa banjar dengan menggunakan sistem Subaknya. Aktivitas keseharian petani sebagian besar hanya menanam padi. Kemudian pada tahun 2013 diselenggarakan lomba Subak yang mendatangkan beberapa instansi diantaranya dari Badan Lingkungan Hidup Kota Denpasar (BLH), Dinas Pertanian, Pusat Pendidikan Lingkungan Hidup Bali (PPLH Bali) dan Pusat Penelitian Lingkungan Hidup Universitas Udayana (PPLH Unud). salah satu dari intansi tersebut yaitu BLH menilai bahwa Subak Sembung bagus, kemudian ada pengkajian dari BLH dengan PPLH Unud untuk menjadikan Subak Sembung sebagai Destinasi Ekowisata.

Ekowisata merupakan kegiatan wisata yang menaruh perhatian besar terhadap kelestarian sumber daya pariwisata. Masyarakat Ekowisata Internasional mengartikannya sebagai perjalanan wisata alam yang bertanggungjawab dengan cara mengkonservasi lingkungan dan meningkatkan kesejahteraan masyarakat lokal (TIES, 2000). Akhirnya sebagai pendekatan pengembangan, Ekowisata merupakan metode pemanfaatan dan pengelolaan sumber daya lingkunagn secara ramah lingkungan. Disini kegiatan wisata yang bertanggung jawab terhadap kesejahteraan masyarakat lokal dan pelestarian lingkungan sangat ditekankan dan merupakan ciri khas Ekowisata. (Damanik \& Weber. 2006).

Pengkajian Subak Sembung menjadi destiansi ekowisata yaitu dengan tujuan untuk memotivasi para petani di Subak Sembung agar mempertahankan persawahan mereka yang masih tersisa sehingga tidak beralih fungsi menjadi bangunan-bangunan beton. Salah satu alasan dijadikannya Subak Sembung sebagai sebuah destinasi ekowisata adalah untuk menjaga lingkungan hijau yang masih tersisa secara lestari di tengah Kota Denpasar. Kemudian setelah ditetapkannya Subak Sembung menjadi destinasi ekowisata, masyarakat lokal terutama penduduk asli yang bertempat tinggal di Desa Peguyangan menjadi salah satu pemain kunci dalam kegiatan pariwisata di ekowisata Subak Sembung. Kegiatan ekowisata tersebut yaitu tracking dan cycling dengan menelusuri persawahan Subak Sembung serta terdapat pula kegiatan cooking class, dan belajar membuat canang. Masyarakat lokal yang memiliki lahan persawahan di Subak
Sembung diharapkan ikut berpartisipasi dalam pengembangan ekowisata subak tersebut.

Partisipasi masyarakat lokal saat ini masih sangat minim dan sangat terbatas, khususnya partisipasi dari generasi muda. Melibatkan generasi muda dalam aktivitas kepariwisataan sangat perlu ditingkatkan untuk melatih generasi muda dalam berkreativitas secara mandiri melalui aktivitas kepariwisataan.

Kelompok generasi muda di Desa Peguyangan terdiri dari kelompok sekaa truna truni (STT) yang diklasifikasikan berdasarkan umur dan status perkawinan, yaitu umur 15 tahun keatas dan belum menikah, kelompok wanita tani (KWT) ditentukan berdasarkan umur dan jenis kelamin, serta ibu-ibu PKK dari setiap banjar yang ditentukan berdasarkan profesi. Setiap kelompok generasi muda dapat berpartisipasi secara optimal dalam aktivitas kepariwisataan di ekowisata Subak Sembung. Partisipasi generasi muda dalam aktivitas kepariwisataan dapat berupa pemasukan usulan ide-ide atau gagasan yang dapat membantu pengembangan ekowisata Subak Sembung, karena selain untuk melatih kemandirian generasi muda melalui partisipasi tersebut juga dapat melatih diri generasi muda tentang bagaimana cara mengelola ekowisata Subak Sembung agar kedepannya dapat tetap lestari.

Berdasarkan fenomena-fenomena tersebut, penelitian ini dianggap penting oleh penulis untuk mengetahui bagaimana partisipasi generasi muda dalam pengembangan ekowisata Subak Sembung di Desa Peguyangan, Denpasar Utara.

\section{TINJAUAN PUSTAKA}

\subsection{Deskripsi Konsep}

1. Konsep ekowisata

Konsep ini digunakan untuk mengkaji jenis wiata yang ada di Desa Peguyangan.

2. Konsep sistem irigrasi subak

Konsep ini digunakan untuk mengkaji potensi kearifan lokal yang ada di Desa Peguyangan, dimana subak merupakan salah satu potensi daya tarik ekowisata yang ada di Dsa Peguyangan.

3. Konsep generasi muda

Konsep ini digunakan sebagai tinjauan rentang usia dari generasi muda yang berpartisipasi di Ekowisata Subak Sembung. 
4. Konsep pengembangan

Konsep ini digunakan untuk mengkaji pengembangan Ekowisata Subak Sembung di Desa Peguyangan.

5. Konsep potensi

Konsep potensi ini digunakan untuk mengkaji potensi ekowisata yang ada di Desa Peguyangan.

\subsection{Deskripsi Teori}

Menurut Tosun, tipe partisipasi masyarakat dalam pariwisata ada tiga yaitu spontan, induksi, dan koersif yang akan dijelaskan dalam tabel di bawah ini

\section{Tabel 2.1 Tipologi Partisipasi Masyarakat} Cevat Tosun

\begin{tabular}{|c|c|}
\hline $\begin{array}{l}\text { Tipe } \\
\text { Partisipasi } \\
\text { Masyarakat }\end{array}$ & Karakteristik \\
\hline Spontan & $\begin{array}{lr}\text { Bottom-up; partisipasi aktif; } \\
\text { partisipasi langsung; } \\
\text { partisipasi informal, otentik; } \\
\text { partisipasi di dalam seluruh } \\
\text { pengembangan termasuk } \\
\text { dalam pengambilan keputusan, } \\
\text { implementasi, r berbagi } \\
\text { keuntungan; } \\
\text { produksi bersama; ide masing- } \\
\text { masing partisipasi yang luas; } \\
\text { partisipasi sosial. }\end{array}$ \\
\hline Induksi & $\begin{array}{l}\text { Top-down; partisipasi pasif; } \\
\text { partisipasi tidak langsung; } \\
\text { partisipasi formal; dan } \\
\text { partisipasi pseudo; partisipasi } \\
\text { dalam implementasi dan saling } \\
\text { berbagi keuntungan; pilihan } \\
\text { diantara usulan alternative dan } \\
\text { saran }\end{array}$ \\
\hline Koersif & $\begin{array}{l}\text { Top-down; manipulasi, } \\
\text { partisipasi pasif; partisipasi } \\
\text { formal; partisipasi dalam } \\
\text { implementasi dan tidak saling } \\
\text { berbagi keuntungan; pilihan } \\
\text { diantara usulan alternative } \\
\text { yang terbatas atau tidak ada } \\
\text { pilihan atau paternalisme, non- } \\
\text { partisipasi, }\end{array}$ \\
\hline
\end{tabular}

Sumber: Towards a Typology of Community Participation in the Tourism Development Process Journal, by Cevat Tosun

\section{METODE}

Jenis data yang digunakan dalam penelitian ini menggunakan jenis data kualitatif (Bogdan \& Taylor, 1990). Dalam penelitian ini yang dimaksud data kualitatif yaitu berupa gambaran umum ekowisata subak sembung, mengenai partisipasi generasi muda, serta pengembangan ekowisata subak sembung.

Sumber data yang digunakan dalam penelitian ini yaitu data primer dan sekunder. Data primer dalam penelitian ini adalah hasil wawancara yang di dapat langsung dari pihak pengelola Ekowisata Subak Sembung, Kelian Banjar Pulugambang, dan ketua Sekaa TrunaTruni (STT) Banjar Pulugambang di Desa Peguyangan mengenai kelompok generasi muda, bentuk partisipasi generasi muda dalam pengembangan ekowisata subak sembung, serta upaya untuk meningkatkan partisipasi generasi muda. Data sekunder dalam penelitian ini berupa profil Desa Peguyangan dan laporan tertulis yang berjudul "Studi Kajian Pengembangan Ekowisata Dan Jasa Lingkungan di Subak Sembung, Kelurahan Peguyangan, Kecamatan Denpasar Utara".

Teknik pengumpulan data yang dilakukan dalam penelitian ini yaitu dengan cara observasi secara langsung dengan mengamati keberadaan ekowisata Subak Sembung, wawancara mendalam terhadap beberapa narasumber, antara lain pengelola Ekowisata Subak Sembung, kelian banjar Pulugambang dan ketua sekaa truna-truni (STT) Banjar Pulugambang, Denpasar Utara mengenai partisipasi generasi muda, dan studi kepustakaan yang dilakukan yaitu dengan mengumpulkan data dari buku-buku, dokumentasi, literatur serta hasil penelitian sebelumnya yang berhubungan dengan penelitian yang akan dilakukan (Fauzi dalam Supardi, 2009). Data yang diperoleh dari studi kepustakaan yaitu data dokumen yang berupa laporan Studi Kajian Pengembangan Ekowisata dan Jasa Lingkungan di Subak Sembung, Kelurahan Peguyangan, Kecamatan Denpasar Utara, dan foto-foto yang berkaitan dengan daya tarik Ekowisata Subak Sembung

Teknik penentuan informan dilakukan dengan menentukan informan pangkal yang kemudian informan pangkal tersebutlah yang akan mengarahkan kepada informan kunci untuk memperoleh validitas data (Koentjaraningrat dalam Fitrianto, 2015:43). 
Adapun informan pangkal yaitu Kepala Desa Peguyangan, Denpasar Utara. Dari informan pangkal tersebut kemudian dapat ditemukan informan kuncinya adalah pengelola Ekowisata Subak Sembung, Kelian Banjar Pulugambang, dan ketua sekaa truna-truni (STT) banjar pulugambang Desa Peguyangan, Denpasar Utara.

Teknik analisis data yang digunakan pada penelitian ini adalah teknik analisis data model Miles dan Huberman. Miles dan Huberman dalam Sugiyono (2014:246) mengemukakan bahwa aktifitas dalam menganalisis data kualitatif dilakukan secara interaktif. Aktifitas dalam analisis data tersebut meliputi pengumpulan data, reduksi data, penyajian data, dan penarikan kesimpulan.

\section{HASIL DAN PEMBAHASAN}

\subsection{Gambaran Umum Ekowisata Subak Sembung}

Ekowisata Subak Sembung terletak di banjar pekraman Pulugambang, Desa Peguyangan Kecamatan Denpasar Utara, Kota Denpasar. Lokasi Ekowisata Subak Sembung dapat diakses melalui jalan Ahmad Yani, kemudian menuju Setra Agung Peyuyangan hingga sampai di kawasan Ekowisata Subak Sembung. Dalam Pengembangan Ekowisata Subak Sembung dapat dilihat dari 4 aspek yaitu atraksi/daya tarik, aksesibilitas, fasilitas/ sarana dan prasarana, dan ancillary. Ekowisata Subak Sembung Memiliki Potensi daya tarik yaitu terdapat potensi daya tarik alam dan potensi daya tarik buatan, potensi daya tarik alam yang terdapat di Ekowisata Subak Sembung yaitu potensi flora dan fauna sedangkan potensi daya tarik buatan yang terdapat di Ekowisata Subak Sembung yaitu potensi buatan yang berupa makanan, minuman dan kerajinan tangan.

\subsection{Partisipasi Generasi Muda Dalam Pengembangan Ekowisata Subak Sembung}

Partisipasi generasi muda dalam pengembangan Ekowisata Subak Sembung yaitu berpartisipasi dalam atraksi wisata, guide local, penyambut tamu, dan penjaga stand kuliner di Ekowisata Subak Sembung. Namun dari partisipasi generasi muda masih sangat terbatas. Terbatasnya partisipasi generasi muda yang berpartisipasi dikarenakan Ekowisata Subak Sembung masih tergolong baru jadi partisipasi generasi muda hanya cukup dari satu banjar saja yaitu Banjar Pulugambang.

Partisipasi generasi muda yang berbartisipasi aktif dalam atraksi wisata di Ekowisata Subak Sembung hanya dari Banjar Pulugambang, dikarenakan banjar Pulugambang merupakan Banjar yang paling terdekat dari Ekowisata Subak Sembung dan Ekowisata Subak Sembung merupakan wilayah dari Banjar Pulugambang. Generasi muda yang berpartisipasi yaitu dari kalangan sekaa turunatruni (STT), kelompok wanita tani (KWT), dan ibu-ibu PKK dari Banjar Pulugambang itu sendiri.

Berikut partisipasi yang di lakukan oleh generasi muda dari Banjar Pulugambang yaitu sebagai berikut:

1) Partisipasi Generasi Muda dari Sekaa TrunaTruni (STT) Banjar Pulugambang

Generasi muda dari STT ikut serta berpartisipasi dalam aktivitas kegiatan eventevent yang di selenggarakan oleh pengelola Ekowisata Subak Sembung. Adapun keterlibatan STT tersebut yaitu sebagai penyambut tamu, penjaga stand makanan dan minuman, penjaga stand kerajinan tangan, generasi muda dilibatkan juga sebagai guide local dalam aktivitas wisatawan, dekorasi tempat untuk mengadakan event, ikut menjaga kebersihan lingkungan, memandu wisatawan dalam pembuatan canang, pemandu outbound, mengajarkan wisatawan melukis, mengajar menari, serta mengadakan event lomba memancing untuk meningkatkan perekonomian petani juga sekaligus cara untuk mempromosikan ekowisata yang dimilikinya.

2) Partisipasi Generasi Muda dari Kelompok Wanita Tani (KWT) Banjar Pulugambang

KWT berartisipasi dalam penjualan serta pengolahan makanan yang dapat di jual di Ekowisata Subak Sembung seperti kripik bayam, kripik singkong, jajanan bali dan lain sebagainya. Dalam proses pembuatan makan tersebut, KWT dapat langsung mengambil bahan-bahan yang digunakan untuk membuat keripik dari hasil pertanian di persawahan Subak Sembung. Kemudian keripik-keripik tersebut di kemas secara baik dan di jual di Ekowisata Subak Sembung sebagai makanan yang dapat di beli dan di konsumsi oleh wisatawan. Disamping itu KWT dapat menjual sayuran yang ditanam di lahan persawahan 
Subak Sembung secara langsung jika ada wisatawan yang berkunjung ke Ekowisata Subak Sembung dengan diberi nama (wisata petik sayur). Jadi wisatawan dapat langsung memetik dan membeli sayuran-sayuran yang ada di Ekowisata Subak Sembung.

3) Partisipasi Generasi Muda dari Ibu-ibu PKK Banjar Pulugambang

Ibu-ibu PKK berpartisipasi dalam penjualan prodak kerajinan tangan serta langsung mengolah kerajinan tangan tersebut dengan menggunakan proses 4R (Reduce, Reuse, Recycle dan Replace). Jenis-jenis prodak yang di produksi oleh ibu-ibu PKK dari kalangan Banjar Pulugambang yaitu seperti tas-tas, dompet, gantungan kunci, setra hiasan-hiasan lainnya yang berasal dari barang bekas yang sudah tidak terpakai lagi kemudian dipilih dan di olah menjadi produk-produk yang berkualitas dan sangat layak untuk diperjual belikan kepada wisatawan yang berkunjung ke Ekowisata Subak Sembung.

Setelah adanya Ekowisata, kalangan ibu-ibu PKK baru mulai berinisiatif untuk berpartisipasi dalam pengembangan ekowisata Subak Sembung, selain itu mereka juga menyadari bahwa Ekowisata Subak Sembung merupakan milik mereka dan menyadari bahwa adanya Ekowisata di Desa mereka yang patut untuk dijaga dan dilestarikan serta bermanfaat sebagai pertahanan lahan persawahan yang masih tersisa di Kota Denpasar, sehingga penting untuk dipertahankan oleh generasi penerus agar tidak menjadi punah. Berikut gambar-gambar kerajinan tangan yang di perjual belikan sebagai kebutuhan wisatawan
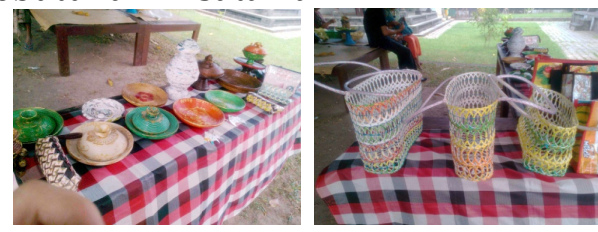

Gambar 4.1 prodak kerajinan tangan di Ekowisata Subak Sembung

Sumber: Observasi, 02 juni 2016

\subsubsection{Tipologi Partisipasi Generasi Muda Banjar Pulugambang Dalam Aktifitas Kepariwisataan Ekowisata Subak Sembung}

Tipologi partisipasi generasi muda yang dihubungkan dengan teori partisipasi masyarakat oleh Cevat Tosun (1999), diketahui bahwa partisipasi generasi muda dalam aktivitas kepariwisataan di Ekowisata Subak Sembung khususnya dari Banjar Pulugambang termasuk kedalam jenis partisipasi secara spontan. Hal tersebut dikarenakan partisipasi yang dilakukan oleh generasi muda khususnya dari Banjar Pulugambang bersifat sukarela, tanpa ada paksaan dari pihak lain dan tidak adanya campur tangan dari pemerintah dalam kegiaatan partisipasi yang dilakukan oleh generasi muda banjar Pulugambang dalam aktivitas kepariwisataan di Ekowisata Subak Sembung.

Generasi muda dari Banjar Pulugambang berpartisipasi secara aktif dalam aktivitas kepariwisataan seperti terlibat dalam kegiatan event-event yang di selenggarakan oleh pengelola Ekowisata Subak Sembung yaitu sebagai penyambut tamu, dikelompokan dalam kepanitian, penjaga stand makanan dan minuman, penjaga stand aksesoris kerajinan tangan, dilibatkan pula sebagai guide local, membantu dalam pendekorasian, menjaga lingkungan, serta melaksanakan event-event seperti lomba memancing, memandu dalam pembuatan canang, outbound, mengajarkan wisatawan melukis serta mengajarkan wisatawan menari. Berdasarkan teori partisipasi dari Tosun tersebut menyatakan bahwa partisipasi generasi muda Banjar Pulugambang termasuk kedalam katagori tipe partisipasi spontan.

\subsubsection{Upaya Meningkatkan Partisipasi Generasi Muda Dalam Aktivitas Kepariwisataan Ekowisata Subak Sembung}

Terbatasnya partisipasi generasi muda dari Banjar-Banjar lainnya maka ada beberapa upaya untuk meningkatkan partisipasi generasi muda dalam aktivitas kepariwisataan Ekowisata Subak Sembung yaitu:

1. Upaya-Upaya dari pengelola Ekowisata Subak Sembung

Mensosialisasikan ke Banjar-Banjar yang tersebar di sekitar Desa Peguyangan, bahwa ada Ekowisata Subak Sembung yang merupakan milik Desa Peguyangan. Karena dengan kegiatan sosialisasi akan berkaitan dengan upaya meningkatkan pengetahuan dan pemahaman generasi muda tentang pengembangan Ekowisata Subak Sembung di Desa Peguyangan.

2. Upaya-Upaya dari ketua sekaa truna-truni (STT) Banjar Pulugambang 
a) Legal Formal yaitu dengan cara merekrut generasi-generasi muda dari Banjar-Banjar lainnya melalui aturan-aturan secara legal formal untuk ikut berpartisipasi dalam aktivitas kepariwisataan Ekowisata Subak Sembung di masa yang akan datang.

b) In formal yaitu dengan cara mengajak dan mengundang generasi-generasi muda dari Banjar lainnya untuk melakukan aktivitas di Ekowisata Subak Sembung, seperti jalan santai, bersepeda serta mengajak generasi muda dari Banjar lain untuk ikut serta berpartisipasi dalam event-event yang diadakan di Ekowisata Subak Sembung.

\section{SIMPULAN DAN SARAN \\ 5.1 Simpulan}

Pengembangan Ekowisata Subak Sembung dapat dilihat dari 4 aspek yaitu atraksi/daya tarik, aksesibilitas, fasilitas/ sarana dan prasarana, dan ancillary. Potensi daya tarik Ekowisata Subak Sembung yang utama adalah alam, antara lain flora dan faunanya serta potensi daya tarik buatan yang cukup beragam.

Partisipasi generasi muda dalam aktivitas kepariwisataan Ekowisata Subak Sembung masih sangat terbatas dari Banjar-Banjar lainnya yang tersebar di Desa Peguyangan. Dikarenakan sumber daya manusia yang masih sangat terbatas, terbatasnya sumberdaya manusuia yang berpartisipasi dikarenakan Ekowisata Subak Sembung masih tergolong baru jadi partisipasi generasi muda hanya cukup dari satu banjar saja yaitu Banjar Pulugambang. Generasi muda dari Banjar Pulugambang berpartisipasi secara aktif dalam aktivitas kepariwisataan khususnya pada aktraksi wisata seperti terlibat dalam kegiatan event-event yang di selenggarakan oleh pengelola Ekowisata Subak Sembung yaitu sebagai penyambut tamu, dikelompokan dalam kepanitian, penjaga stand makanan dan minuman, penjaga stand acsessories kerajinan tangan serta dilibatkan pula sebagai guide local, membantu dalam pendekorasian, menjaga lingkungan, melaksanakan event-event seperti lomba mancing, memandu dalam pembuatan canang, outbound, mengajarkan wisatawan melukis serta mengajarkan wisatawan menari. Berdasarkan teori partisipasi dari Tosun tersebut menyatakan bahwa partisipasi generasi muda Banjar Pulugambang termasuk kedalam katagori tipe partisipasi spontan.

\subsection{Saran}

Saran yang dapat disampaikan yaitu sebagai berikut:

1. Untuk memenuhi kebutuhan fasilitas bagi wisatawan di Ekowisata Subak Sembung agar menyediakan pelayanan tambahan (ancillary service) seperti pembuatan kantor depan atau office, kantor pos satpam, Tourist Information Center (TIC), serta penataan parkir yang lebih memadai. Karena pelayanan tambahan (ancillary service) sangat dibutuhkan oleh wisatawan mancanegara maupun wisatawan nusantara.

2. Dalam pengembangan Ekowisata Subak Sembung agar lebih mengefektifkan partisipasi generasi muda dari banjar lain yang tersebar di wilayah Desa Peguyangan untuk dapat ikut serta dalam aktivitas kepariwisataan di Ekowisata Subak Sembung. Memberi kesempatan generasi muda dari banjar lain untuk mengemukakan pendapat sehingga tercipta pemahaman bersama tentang bagaimana pengembangan Ekowisata Subak Sembung untuk kedepannya, sehingga memberi manfaat bersama secara ekonomis.

\section{DAFTAR PUSTAKA}

Aziz Muslim. 2007. Pendekatan Partisipatif Dalam Pemberdayaan Masyarakat. Jurnal Aplikasi IlmuIlmu Agama. Vol. VIII. No. 2.

Bambang Munas Dwiyanto. 2011. Model Peningkatan Partisipasi Masyarakat dan Penguatan Sinergi Dalam Pengelolaan Sampah Perkotaan. Jurnal Ekonomi Pembangunan. Vol. 12. No. 2. Fakultas Ekonomi, Universitas Diponegoro.

Bungin, Burhan. 2012. Metodologi Penelitian Kualitatif: Akulturasi Metodologi ke Arah Ragam Varian Kontemporer. Jakarta : Rajawali Pres

Damanik Janianton, Helmut F. Weber. 2006. Perencanaan Ekowisata Dari Teori ke Aplikasi. Yogyakarta : Pusat Studi Pariwisata (PUSPAR) UGM.

Gigih Swasono Pardana Putra. Partisipasi Pemuda Dalam Pengembangan Agrowisata di Desa Berjo, Ngargoyoso, Karanganyar. Jurnal Ilmiah Pendidikan Sosiologi Antropolog. Vol. 3. No. 1. Universitas Sebelas Maret Surakarta.

Gunawan, Imam. 2013. Metodologi Penelitian Kualitatif Teori dan Praktik. Jakarta : PT Bumi Askara

Muljadi A.J, H. Andri Warman. 2014. Kepariwisataan dan Perjalanan. Jakarta: Rajawali Pres.

Ravael Modestus Ziku. 2015. Volume 2 Nomor 1. Partisipasi Masyarakat Desa Komodo Dalam Pengembangan Ekowisata di Pulau Komodo. 
Rezki Teguh Sulistiyana, Djamhur Hamid, Devi Farah Azizah. 2015. Pengaruh Fasilitas Wisata dan Harga Terhadap Kepuasan Koonsumen (Studi Pada Museum Satwa). Jurnal Administrasi. Vol. 25. No 1. Fakultas Ilmu Administrasi. Universitas Brawijaya Malang

Sugiyono. 2014. Metode Penelitian Manajemen. Bandung : Alfabeta, CV.

Summeng, Andi Mappi. 2001. Cakrawala Pariwisata. Jakarta : Balai Pustaka

Sutawan nyoman. 2008. Organisasi dan Manajement Subak di Bali. Denpasar: Bali Post.

Suwantoro, Gamal. 1997. Dasar-Dasar Pariwisata. Yogyakarta: Andi Yogyakarta.

Tosun, C. (1999). Towards a Typology of Community Participation in the Tourism Development Process. An International Journal of Tourism and Hospitality Research, 10 (2), 113-134.

Yoeti, Oka A. 1997. Perencanaan dan Pengembangan Pariwisata. Bandung: Angkasa.

Yoeti, Oka A. 2013. Tours And Travel Marketing. Jakarta : Pradnya Paramita 